\title{
Analysis of the Jean Pants Street Fashion for Men in Seoul, $2012^{+}$
}

\author{
Lee Minjeong
}

Lecturer, Dept, of Clothing and Textiles, Sookmyung Women's University

\begin{abstract}
This study researched the jeans street fashion for young men looked like 20 s and 30 s in Seoul, and analyzed jeans by silhouette by fit and color by washing. The photos were of jeans from the waist to the bottom; and among a total of 1,159 images, 847 images that could be analyzed were selected and used for the analysis. From the images used in the analysis, the jeans fits were categorized according to silhouette and color that were used for the visual selection. As a result, young men preferred fashion jeans like slim or skinny jeans. Most of the tight fitting skinny and slim jeans were slim baggy style jeans, like low waist \& long rise with a low back york, which was a key trendy pants style. The jeans color analysis by washing finish showed that dark jeans were most frequently, most of the dark jeans had the original denim color based on the non or normal wash techniques. It is hoped that the results of this study can be used as basic data for the development of designs for jeans brands.
\end{abstract}

Key Words : Denim pants, Jeans, Jean pants, Men's fashion, Street fashion

\section{Introduction}

The recent men's fashion trend in Korea is changing as fast as the women's fashion trend and tends to be identified with the latter. Trendy words in Korea like "Kotminam (Beautiful men)," "Chocolate abs," or "Chadonam (Chic urban men)" represent the lifestyle of men in their 20s and 30s who are sensitive to fashion. Reflecting such a trend, the fashion market for men's makeup and accessories has rapidly grown. As such, men who used to be insensitive to fashion now lead the fashion market more proactively than women, and the men's fashion market has become diversified and subdivided ${ }^{1)}$. Accordingly, the fashion market for men's wear has emerged as a new trend.

Until now, the market for men's wear had been dissected into formal brands and semi-formal casual brands. In keeping with the current market trends, the growth of formal brands has dwindled, whereas that of the market

\footnotetext{
${ }^{+}$This study was sponsored by Basic House Corporation

Corresponding author: Lee Minjeong, Tel.+82-2-710-9461, Fax.+82-2-710-9461, E-mail: terry111@hanmail.net
} 
for casual brands has been further subdivided into unisex casual brands and semi-formal casual brands, a move led mainly by specialty jeans brands. Also, the recent changes in the social atmosphere, such as the five-day workweek and class system, energy-saving policies due to global warming, and other uniform work simplification policies has become a key factor of the growth of the casual wear market, which is changing men's clothing style. Among clothing items, jeans are popular with both the young and old as well as between men and women, because they can be easily coordinated with other items regardless of the time and place. Consequently, jeans have become key fashion items.

Previous studies on jeans have focused on jeans design patterns ${ }^{2 / 3)}$, fashion design using denim $^{4 / 566)}$, analysis of women's jeans style ${ }^{7 / 899)}$, and surveys on men's denim fashion ${ }^{10111}$. Other studies have also concentrated on analyzing female consumers' purchasing trends and denim washing finishes. As such, despite the diversification of men's fashion and the growth of the jeans market, little research has been conducted on analyzing trends in men's jeans.

Therefore, to determine the fashion needs and styles of men in their 20s and 30s whose fashion sense is diversifying and becoming elegant and upgraded, this study examines young men's jeans trends based on a street fashion survey on jeans, and offers basic data for the establishment of a men's jeans design strategy for Korean clothing brands. The results of this study will also be used as basic data for the establishment of a men's jeans design strategy for Basic House Corporation.

\section{Background}

\section{Korean jeans market trend}

Since the market launch of Levi Strauss's Levi's brand in 1853, jeans have continued to advance through various changes. They may be the only clothing item that consumers of all ages have consistently loved. It is believed to be at around the 1950s when jeans were first introduced in Korea by US soldiers who fought in the Korean War. Then they became a symbol of the youth in the 1970s who resisted the established generation's lazy attitude and wrong policies or who opposed the Yushin dictatorship at that time, or a symbol of the youth who sought freedom and romanticism, centered on acoustic guitar singer-songwriters. Currently, jeans are not only popular clothing items for all ages but also a key statement in fashion.

According to the Korea Fashion Market Trend $(2012)^{12)}$, the Korean clothing market in 2011 was valued at 29.3051 trillion won. Of this, casual clothing accounted for $34.9 \%$ of the market at 6.0107 trillion won, and jeans, for $6.7 \%$, the sixth leading item among a total of 14 clothing items in the market. Casual men's clothing accounted for $50 \%$ of the total casual wear market, in which the market size was in the order of jumpers $>$ t-shirts $>$ jackets $>$ long pants $>$ jeans. This demonstrates why the fashion market, which used to be concentrated on women's wear, has to focus on menswear and jeans.

The casual jeans sales of major Korean department stores from January to November 2011, according to Fashion Channel, show that the market is led by Guess Jeans > Calvin Klein Jeans > Buckaroo Jeans > Levi's, in that order $^{13)}$. As such, jeans users prefer imported premium jeans brands that are expensive but 
stylish to Korean brands. Young consumers also prefer trendy, stylish, and expensive imported premium jeans that are not only functional but also fit well and are comfortable to wear. Levi's 501 or Engineered Jeans were very popular among men in their 20s and 30s, and recently, imported premium brands like True Religion Jeans, Diesel Jeans, Robin's Jean, and Nudie Jeans led the Korean men's jeans market.

\section{Categorization of jeans styles}

Jeans refer to pants made with denim, which is a thick indigo or bleached cloth with $20 \mathrm{~S}$ or smaller warp threads and thinner weft threads in $2 / 1$ or $3 / 1$ twill $^{(4)}$. Due to such a unique weaving technique, denim has a unique blue color, and through various washing finish methods, can have diverse colors. A common washing finish method for jeans is garment washing, which is shown in $\langle$ Table 1$\rangle$. It is the most representative washing finish method for jeans brands. ${ }^{15)}$

Generally, jeans brands categorize the styles of jeans into their silhouette based on the degree of their fit, color based on their washing finish, and details based on their pockets or stitches. Yangsoo $\mathrm{Kim}^{16)}$ categorized denim styles in women's collections into "Silhouette \& Fit," "Color \& Texture," and "Washing Finish", whereas Chanju Kim and Mikyung Ro ${ }^{17)}$ analyzed denim pants by color, silhouette, and detail in their comparative study of men's global denim fashion. This study surveys the jeans style of Levi's, the first and oldest special jeans brand, based on which it analyzes men's street jeans fashion $^{18)}$.

Levi's' jeans styles can generally be divided into "Silhouette by Fit" and "Color by Wash." Others are categorized according to specific designs and other unique characteristics or details. "Silhouette by Fit" is further divided, based on the degree to which the pair of jeans fits the body, into "Skinny," wherein the jeans closely fit the waist to the bottom; "Slim," wherein the jeans have little loose with a straight line from the knee to the bottom; and "Regular Straight," wherein the jeans have more loose with a straight line from the hip to the bottom $\left\langle\right.$ Table 2> and <Figures 1-3> ${ }^{1920)}$ This categorization excludes boots-cut or short pants that are often seen in women's jeans. "Color by Wash" is also subdivided into "Light," in which the jeans has a light color due to bleaching and more frequent washing; "Medium," in which the jeans has a mid-level blue color; "Dark," in which the jeans has denim's original indigo color due to non-washing or normal washing; "Black \& Grey," in which the jeans has a black color; and "Vintage," in which the jeans appears to have been recycled or used with various washing finish methods $\langle$ Table 3$\rangle$ and <Figures $4-8>^{21122)}$.

A recent hot trend in jeans is Skinny for both men and women. As shown in <Table 4>, low-waist \& long-rise with a low back york, a slim baggy style, is a trend in men's jeans; and dark blue with normal or non-wash that minimizes the washing finish, which is harmful to the environment, is also gaining momentum $\left\langle\right.$ Figure 9 ${ }^{233}$. In women's jeans, skinny and short denim pants like stockings are popular $\langle\text { Figure } 10\rangle^{24)}$.

\section{Method}

\section{Target}

To analyze the jeans fit preferred by young men looked like 20s and 30s, a street fashion 
$<$ Table 1> Garment washing finish methods

\begin{tabular}{|c|c|}
\hline Type & Method \\
\hline Normal Wash & $\begin{array}{l}\text { Also called One Wash or Regular Wash, this is a washing technique with a } \\
\text { one-time detergent and desizing agent. It makes jeans smooth and brings out } \\
\text { the natural color of denim. }\end{array}$ \\
\hline Stone Wash & $\begin{array}{l}\text {.After the pre-processing (scouring and desizing), the stone process is } \\
\text { performed. It is important to have enough pumice stones. Once the conditions } \\
\text { are set, the machine is run to create even and elegant patterns. If run for a long } \\
\text { time and excessively, however, the jeans' bottom or waist line may be damaged. } \\
\text { The resulting color is blue, brighter than with the normal wash. }\end{array}$ \\
\hline Stone Bleached & $\begin{array}{l}\text { Bleaching is done to mask damage and remove the pigment in textile, and } \\
\text { decoloring refers to all processes that use bleaching agents. It can create a } \\
\text { brighter and cooler blue color than can stone wash. }\end{array}$ \\
\hline Bio Wash & $\begin{array}{l}\text { This can produce the same effect as that of stone wash (in terms of the color } \\
\text { or pattern) but with cellulase, not stone, and results in a smoother finish and a } \\
\text { softer color than with pumice stone. }\end{array}$ \\
\hline Bio Stone Wash & $\begin{array}{l}\text { By appropriately mixing cellulase and pumice stone, both the rough worn-out } \\
\text { effect of stone wash and the soft color of cellulase finish can be produced with } \\
\text { this technique. The degree of the worn-out effect in the color and surface can } \\
\text { be controlled according to the intended design. }\end{array}$ \\
\hline Chemical Wash & $\begin{array}{l}\text { This washing technique in which bleaching agents are used is suitable for partial } \\
\text { decoloring and creating patterns or wrinkles. }\end{array}$ \\
\hline $\begin{array}{l}\text { HardRock Wash, } \\
\text { Snow Wash }\end{array}$ & This can produce an older look than the existing jeans washing techniques. \\
\hline Over Dyeing Wash & $\begin{array}{l}\text { An additional dyeing process is performed on products after the washing finish, } \\
\text { like bio wash or stone wash, to produce a unique color on top of the original } \\
\text { denim indigo color. This is an advanced washing process that combines washing } \\
\text { techniques and dyeing techniques to satisfy consumers' need for diverse colors. }\end{array}$ \\
\hline Sand Wash & $\begin{array}{l}\text { This technique involves washing jeans after cutting parts of it with abrasive sand } \\
\text { shot with compressed air. It can produce a worn-out look on the hips and } \\
\text { thighs. }\end{array}$ \\
\hline Brush Wash & $\begin{array}{l}\text { This technique consists of three processes in which a sandpaper brush, a short } \\
\text { brush, and a chemical brush are used to produce a worn-out look. }\end{array}$ \\
\hline Cat Wash & $\begin{array}{l}\text { This processing technique forms a pattern that looks like a cat's whiskers by } \\
\text { brushing the wrinkled parts of the jeans with sandpaper to decolor them so as to } \\
\text { create the whiskers pattern. }\end{array}$ \\
\hline Embossing Wash & $\begin{array}{l}\text { This is a processing technique that creates a naturally worn-out look on the } \\
\text { lower abdomen, the back of the knees, and the bottom. After creating wrinkles } \\
\text { on the jeans parts that need processing, wrinkle-free agents are applied; and } \\
\text { after heat-setting, sandpaper is used to brush out the parts. }\end{array}$ \\
\hline
\end{tabular}


$<$ Table 2> Silhouette-by Fit chart

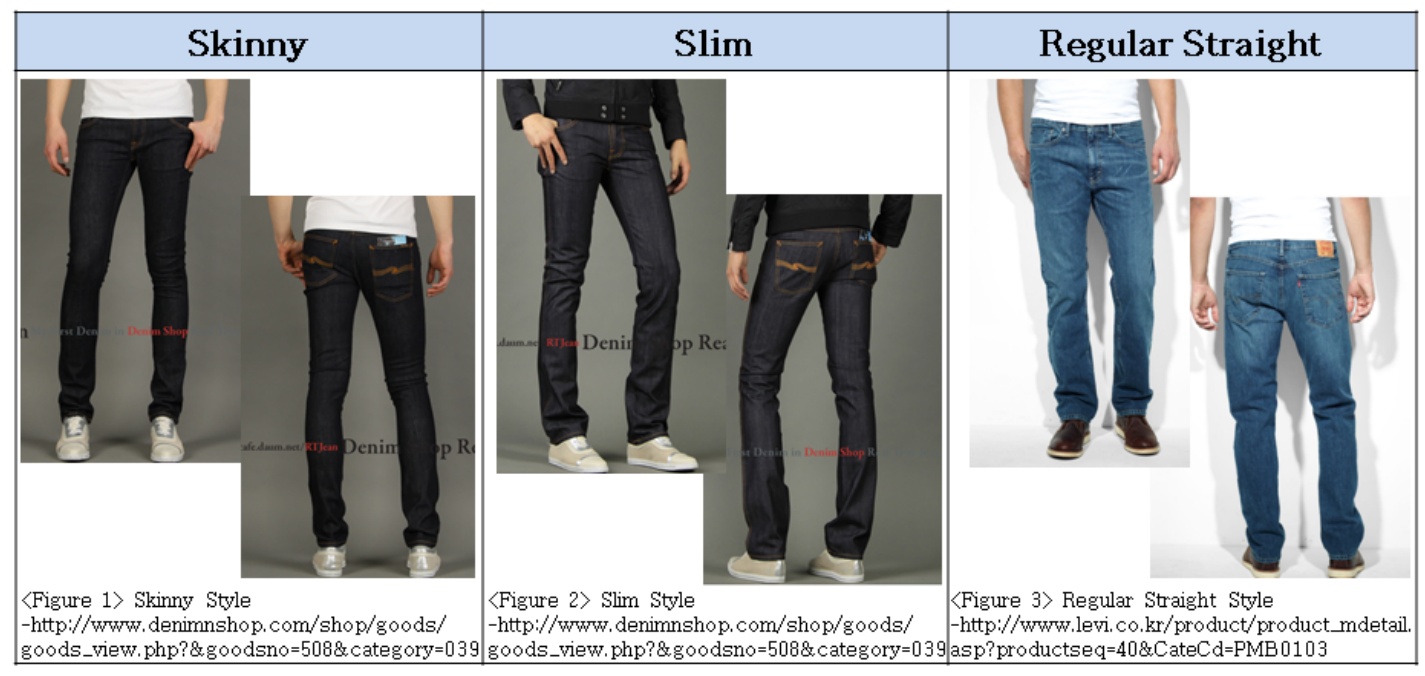

$<$ Table 3> Color-by Wash chart

\begin{tabular}{|c|c|c|c|c|}
\hline Light & Medium & Dark & Black \& Grey & Vintage \\
\hline $\begin{array}{l}\text { SFigure 4> light Color } \\
\text {-http://www.denimnshop.com } \\
\text { /shop/goods/goods_view.php } \\
\text { ?\&goodsno=1674\&category } \\
\text { =039 }\end{array}$ & $\begin{array}{l}\text { <Figure 5>Medium Color } \\
\text {-http://www.levi.co.kr/ } \\
\text { product/product_mdetail.asp } \\
\text { ?productseq=40\&CateCd } \\
=\text { =PMB0103 }\end{array}$ & $\begin{array}{l}\text { <Figure 6> Dark Color } \\
\text {-http://wwww.levi.co.kr/ } \\
\text { product/product_mdetail.asp } \\
\text { ?productseq=12\&CateCd } \\
=\text { PMB0102 }\end{array}$ & $\begin{array}{l}\text { KFigure 7> Black \& Grey Color } \\
\text {-http://www.levi.co.kr/ } \\
\text { product/product_mdetail. asp? } \\
\text { productseq=9\&.CateCd } \\
=\text { =PMB 0101 }\end{array}$ & $\begin{array}{l}\langle\text { Figure 8> Vintage } \\
\text {-http://www.denimnshop. } \\
\text { com/shop/goods/goods } \\
\text { view,php?\&goodsno=1679\& } \\
\text { category=032 }\end{array}$ \\
\hline
\end{tabular}

research was conducted. The survey was administered from April 12 to June 10, 2012, from 4 to 6 p.m. on weekdays, when college students frequently ply the streets. The areas covered by the survey were from Shinchon Hyundai Department Store to the main entrance of Yonsei University, the Hongik University area, Gwanghwamun Plaza, Myeongdong, and Insadong to Samcheongdong, which young college students frequent. Photos of the jeans that they wore were taken with digital cameras. The pictures were of jeans from the waist to the bottom; and among a total of 1,159 images, 847 images that could be analyzed were selected and used for the analysis. The data were categorized by two jeans fashion designers, 
three students majoring in fashion design, and the author.

\section{Analysis method}

From the images used in the analysis, the jeans fits were categorized according to silhouette and color. As shown in $\langle$ Tables 2, 3>, the silhouette and color tables were used for the visual selection. Based on the Levi's Jeans Style Categorization, the styles were first categorized by fit into skinny, slim, and regular straight $<$ Table 2>. Second, they were further categorized and compared according to their height from the waist to the hip, and the height of the back york, into low-waist \& long-rise with a low back york and low-rise with a standard back york, which is the currently popular slim baggy pants style, as shown in <Figure 9>. Depending on the degree of the washing finish, the color was first categorized into light, medium, dark, blue \& gray, and vintage, and analyzed <Table 3>. Next, according to the silhouette, the frequency of the jeans shown in the images was analyzed by color. Finally, the data were coded by silhouette and color, and a frequency analysis was conducted using SPSS 18.

\section{Results}

\section{Silhouette-by Fit}

The silhouette analysis of the images based on <Table 2> showed the results presented in <Figure 11 , as follows: $49.1 \%$ of the jeans had a regular straight style, followed by $46.4 \%$ slim and $4.5 \%$ skinny. The comparative analysis of the current trends, low-waist \& long-rise with a

$<$ Table 4> 2012 S/S Hot trend of jean pants

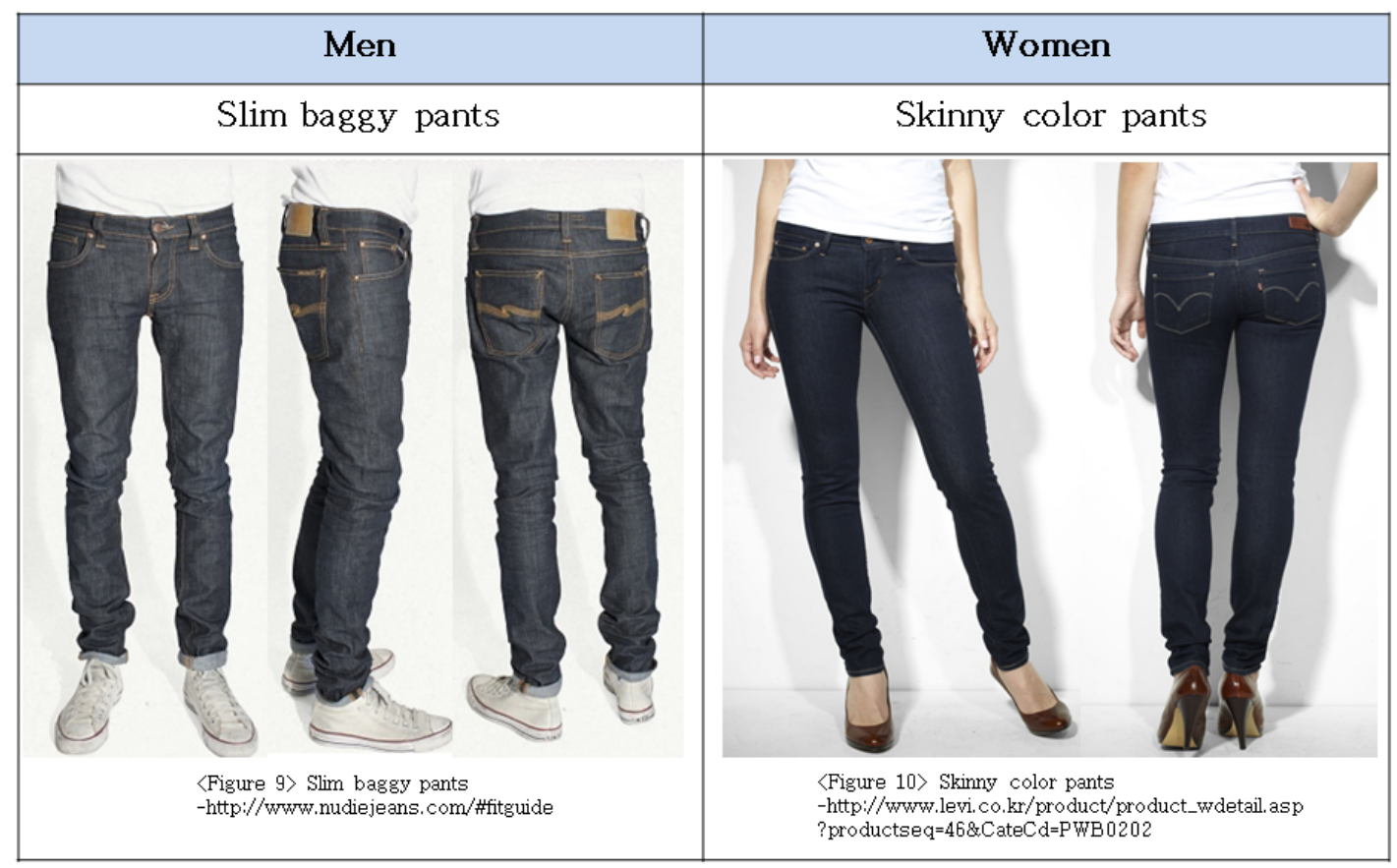


low back york and low-rise with a standard back york, which are slim baggy pants styles, showed that the frequencies of the skinny jeans were identical; $41 \%$ of the slim jeans were low-waist \& long-rise with a low back york and $59 \%$ were low-rise with a standard back york; and $95 \%$ of the regular straight jeans were low-rise with a standard back york $\langle$ Table 5>.

Low-waist \& long-rise with a low back york, a slim baggy pants style, has loose from the hip to the knee in skinny jeans, and a very tight bottom at the ankle <Figure 12>. The loose fit in the skinny jeans is similar to that in low-rise pants with a standard back york <Figure 13>.

Such results showed that while skinny jeans were trendy in both men and women, they were popular among some men who were early adopters in their early 20s. Also due to the men's physical characteristics, they preferred slim or regular jeans to skinny jeans. Overall, however, men preferred jeans styles with less loose than in the past. Men who wore regular straight jeans had a significantly low frequency (5\%) of use of low-waist \& long-rise with a low back york jeans, a slim baggy pants style, than those who wore skinny or slim jeans. This shows that men who wear regular straight jeans prefer basic casual jeans that are not sensitive to a trend.

\section{Color-by Wash}

<Figure 14> shows the frequency results of the color analysis by washing finish from the images collected by criteria in $\langle$ Table 3$\rangle$. A dark color was the most frequently recognized at $57.5 \%$, followed by the medium at $24.7 \%$, the vintage look at $8.3 \%$, the black and gray color

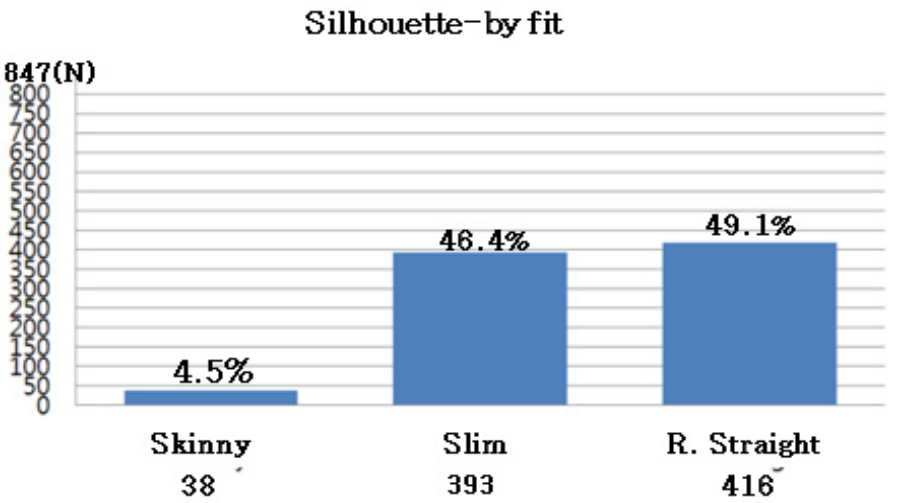

<Figure 11> Frequency of Silhouette-by Fit

$<$ Table 5> Frequency of rise with back yoke length (\%)

\begin{tabular}{c|c|c|c}
\hline \hline 구분 & Skinny & Slim & $\begin{array}{c}\text { Regular } \\
\text { Straight }\end{array}$ \\
\hline Low waist \& long rise with low back yoke & $19(50)$ & $161(41)$ & $20(5)$ \\
\hline Low rise with standard back yoke & $19(50)$ & $232(59)$ & $396(95)$ \\
\hline Total & $38(100)$ & $393(100)$ & $416(100)$ \\
\hline \hline
\end{tabular}


at $6.3 \%$, and light at $3.2 \%$. Among the dark-colored jeans, half were non- or normal-wash, which resulted in the original denim color <Figure 15>. As for the medium color, images were shown of jeans that were normally washed, bio-stone-washed, catwashed, or sand-washed <Figure 16>. These results were based on visual determination due to the characteristics of a street fashion analysis. As such, most of the dark jeans in this study were based on non- or normal-washing finish techniques, and it is believed that such a result reflects an eco-friendly trend, because washing finish requires excessive water use. In addition, the color of jean pants had not changed, according to change of the season and temperature in this researching term.

The silhouettes, as shown in Table 6, were dark (63.1\%), medium (18.5\%), and others $(18.4 \%)$ in skinny jeans. The others included light, black and gray, and vintage. As for slim jeans, their most frequent color was dark $(60.3 \%)$, followed by dark (54.3\%), medium

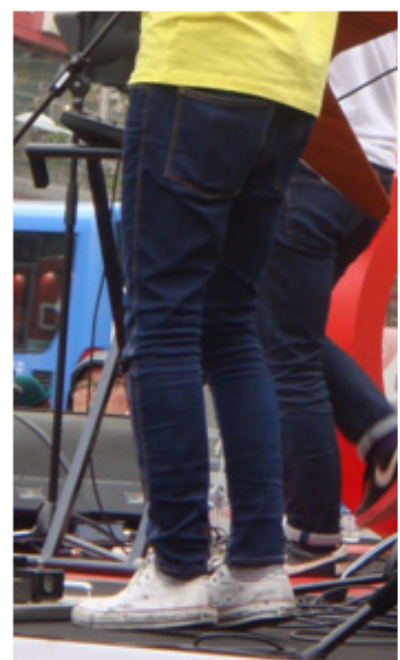

<Figure 12> Skinny -Low waist \& long rise with low back york
(31.7\%), and others (14.0\%). In all silhouettebased analyses, dark jeans accounted for more than half of the total number of jeans, and regular straight jeans constituted $31.7 \%$ of medium-colored jeans. Such results are believed to have been due to the current trend in slim line jeans, such as skinny jeans that look slim and have less loose. Due to the recent tendency of men who became more sensitive to the body line than before, they prefer regular straight dark blue jeans; and because there are more men who prefer the basic style, medium-style jeans were shown more frequently than skinny or slim jeans.

\section{Conclusion}

To determine trends in jean pants among young Korean men, this study surveyed the jeans street fashion for men in their 20s and 30s in Gangbuk, Seoul, and analyzed jeans by silhouette by fit and color by washing. The results

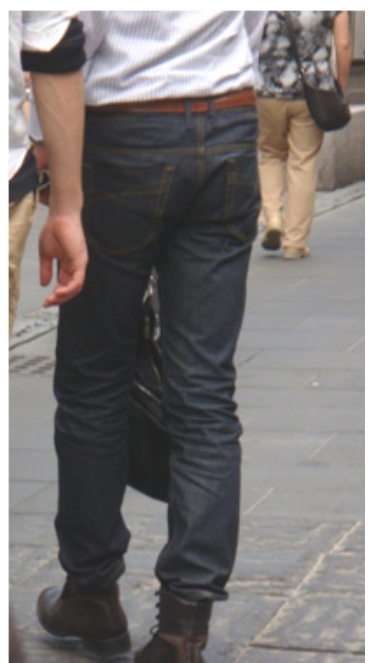

<Figure 13> Slim -Low waist \& long rise with low back york 


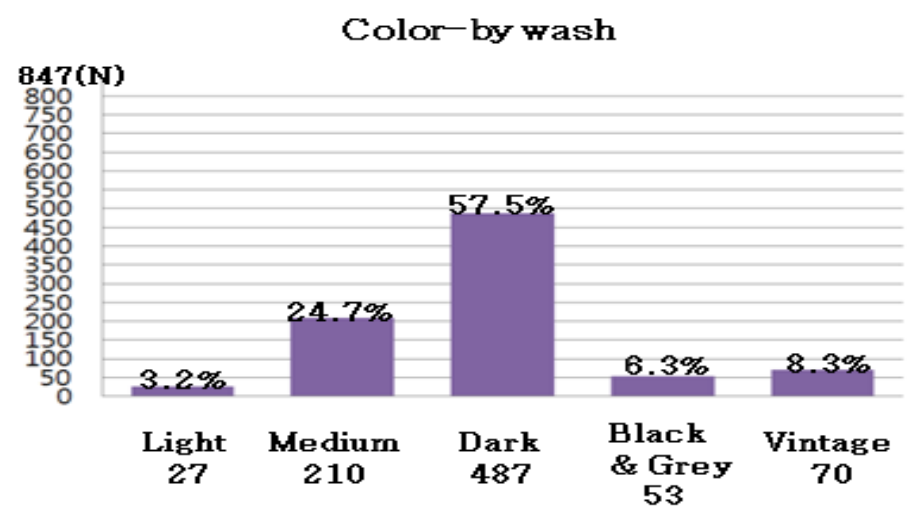

<Figure 14> Frequency of Color-by Wash

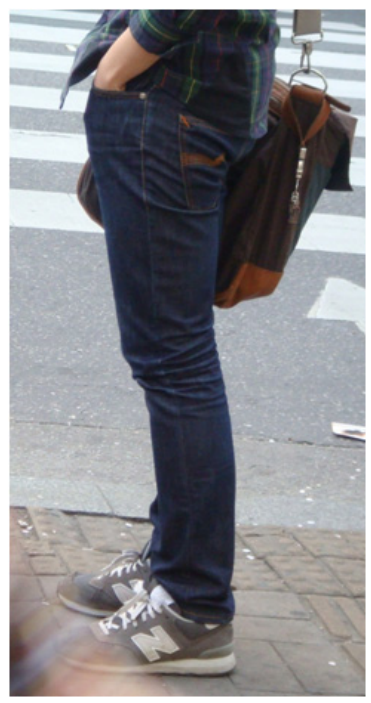

<Figure 15> Dark

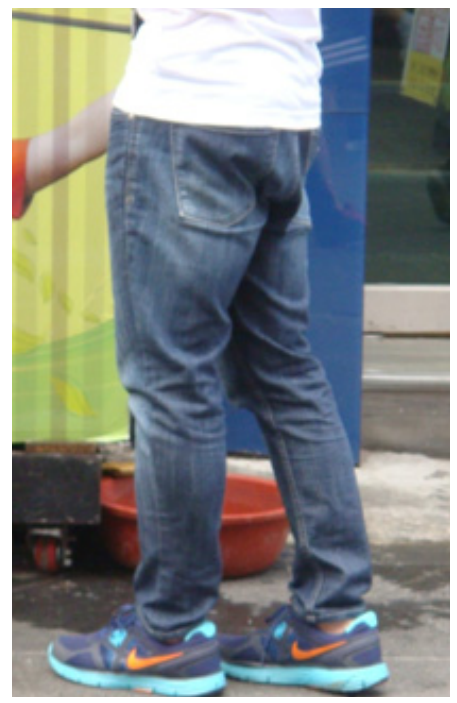

<Figure 16> Medium

$<$ Table $6>$ Color frequency by silhouette (\%)

\begin{tabular}{c|c|c|c}
\hline \hline \multirow{2}{*}{ color silhouette } & Skinny & Slim & R. Straight \\
\hline Dark & $24(63.1)$ & $237(60.3)$ & $226(54.3)$ \\
\hline Midium & $7(18.5)$ & $71(18.1)$ & $132(31.7)$ \\
\hline Others & $6(18.4)$ & $85(21.6)$ & $58(14.0)$ \\
\hline Total & $38(100)$ & $393(100)$ & $416(100)$ \\
\hline \hline
\end{tabular}


of this study are as follows.

The frequency of jeans by silhouette was highest with the regular straight jeans at $49.1 \%$, followed by slim jeans at $46.4 \%$ and skinny jeans at $4.5 \%$. About $50 \%$ of young men preferred a basic jeans style with loose fit, such as regular straight jeans, and the other $50 \%$ also preferred fashion jeans like slim or skinny jeans. Most of the tight-fitting skinny and slim jeans were slim baggy-style jeans, like low-waist \& long-rise with a low back york, which was a key trendy pants style.

The jeans color analysis by washing finish showed that dark jeans were most frequently worn at $57.5 \%$, followed by medium jeans (4.7\%), vintage jeans (8.3\%), black and gray jeans (6.3\%), and light jeans (3.2\%). By silhouette, the dark jeans were mostly skinny, slim, and regular jeans at $63.1 \%, 60.3 \%$, and $54.3 \%$, respectively, and most of the dark jeans had the original denim color based on the nonor normal-wash techniques. It was analyzed that such a result reflected the recent eco-friendly trend in waterless washing techniques as well as the preferences of young men who seek a slim body and fashion.

This study was limited in that the analysis was conducted via visual determination on pictures collected on the street, due to the characteristics of the street fashion survey. Also, this study had both temporal limitations in that the analysis focused on the spring and summer seasons in 2012, and spatial limitations in that the survey was conducted in Gangbuk, Seoul, and therefore, it would not be reasonable to expand the results of this study to other areas. Thus, continuous and multifaceted research on men's jeans trends and efficient research on practical data collection and analysis methodologies are needed. It is hoped that the results of this study can be used as basic data for the development of designs for jeans brands.

\section{Reference}

1) $\mathrm{KOFOTI}(2012), 2012 \mathrm{SS} \mathrm{KFI}$ research analysis \& 2012 FW Market Forecasting, pp.26-33.

2) Uh Mikyung, Suh Mia(2007), "The Development of Jeans Pattern for Stretch Denim Fabrics", Journal of the Korean Fashion \& Costume Design Association, 9(3), pp.191-203.

3) Uh Mikyung, Kim Kyunga \& Suh Mia(2009), "The Development of Jeans Pattern by Washing Finishing", The Research Journal of the Costume Culture, 17(4), pp.535-547.

4) Kim Mina(2002), "Study on Denim for Fashion Design : Research Focusing on the Development of Women's Casual Wear Brand Design in Denim", Unpublished master degree dissertation, The Graduate School of Design Ewha Womans University, Seoul, pp.4-49.

5) Kim Haesoon(2002), "A Study on Clothes Using Denim : Focused on denim with stitches", Unpublished master degree dissertation, The Graduate School of Design Ewha Womans University, Seoul, pp.4-61.

6) Choung Younghee(2000), "A Study on fashion Design Applying Jean Materials", Unpublished master degree dissertation, The Graduate School of Design Ewha Womans University, Seoul, pp.3-45.

7) Yoon Jinah(2007), "Female College Students' Jean Pants Style : With a Focus on Skinny Jean", Journal of the Korea Fashion \& Costume Design Association, 9(1), pp.189 -201 . 
8) Yoon Mikyung, Nam Yunja(2009), " A Study on the Classification of the Women's Pants Silhouettes by Their Pattern Construction", Journal of the Korean Society of Clothing and Textiles, 33(5), pp.741-751.

9) Kim Yangsoo(2011), "Tendency Analysis of Denim Styles Expressed through Women's Collection S/S 2011", The Research Journal of the Costume Culture, 19(5), pp.10611074.

10) Park Hyewon(2006), "A Study on Application of Web-based Fashion Information", Journal of the Korean Society of Clothing and Textiles, 30(11), pp.1519-1530.

11) Kim Chanju, Ro Mikyung(2007), "Comparison of Mens' Denim Fashion in Eastern and Western Cities", Journal of the Korean Society of Clothing and Textiles, 31(7), pp.997-1007.

12) KOFOTI, op.cit., pp.89-123.

13) Department of Fashion, "2012 SS research analysis of Jean Casual Market \& 2012 FW Market Forecasting", FASHION CHANNEL, 2012. 7, pp.24-133.

14) Song Whasoon et al.(2007), Textiles, Kyomunsa, p.240.

15) Editor, "Special Section-Focusing of Denim Washing", Bobbinjournal, 2012. 2, pp.90-103.
16) Kim Yangsoo(2011), op.cit., pp.1061-1074.

17) Kim Chanju, Ro Mikyung(2007), op.cit., pp.997-1007.

18) "Levi's Men Product", Retrieved 2012. 07. 02, from http://www.http://www.levi.co.kr /product /product_m.asp

19) Retrieved 2012. 10. 02, from http://www. denimnshop.com/shop/goods/goods_list.php ?category $=039$

20) Retrieved 2012. 10. 02, from http://www.levi. $\mathrm{co.kr} / \mathrm{product}$

21) Retrieved 2012. 10. 02, from http://www. denimnshop.com/shop/goods/goods_list.php ?category $=039$

22) Retrieved 2012. 10. 02, from http://www. levi.co.kr/product

23) Retrieved 2012. 10. 02, from http://www. nudiejeans.com/\#fitguide

24) Retrieved 2012. 10. 02, from http://www. levi.co.kr/product

25) Lee Minjeong, Chang Heekyung \& Sohn Heesoon(2008. 11. 29), "Comparison of Tendency Street Fashion in China and Korea, Atumn 2008 : Focus on the Yuong Generation between Beijing and Seoul", Proceeding of The Korean Society of Fashion Business, pp.97-105.

26) TBWA KOREA(2008), Blue Revolution, ALMA, pp.1-236.

접수일(2012년 10월 15일),

수정일(1차 : 2012년 11월 5일),

게재확정일(2012년 11월 19일) 